\title{
In the Beginning was the Deed? Discovering the Presence of the Spirit in Social Construction
}

\author{
CARLOS MIGUEL GÓMEZ \\ Universidad del Rosario, Bogotá \\ carlos.gomezr@urosario.edu.co \\ ORCID: 0000-0001-6806-7058
}

\begin{abstract}
The relationship between socio-constructionism and Christian theology has not been sufficiently explored. This paper critically analyses some of the main insights of socio-constructionist theories and suggests that a reinterpretation of the idea of social construction from a theistic perspective can avoid the unresolved problems of its radical versions. The paper argues that an order of meaning, whose origin cannot be reduced to human action, has to be presupposed for practices of social construction to work. This resonates with the belief in God's action in human reality.
\end{abstract}

Keywords: Social sciences and religion; contingency; origin of meaning; anti-realism and diversity.

* This paper is a product of the project Oxford Interdisciplinary Seminars in Science and Religion: Bridging the Two Cultures of Science and the Humanities 2015-2016, organized by Scholarship and Christianity in Oxford (SCIO) with funding from Templeton Religion Trust. I am deeply grateful to the SCIO team and my fellow participants.

Scientia $e t$ Fides $6(1) / 2018,53-77$ 


\section{Introduction}

While trying to translate the first verse of St. John's Gospel, in a way which could capture the active character of the Logos in creation, Goethe's Dr. Faust, just before his first encounter with Mephistopheles, arrived at a formulation that anticipated the philosophical transformations to come and that encapsulates a leit motiv of contemporary social thinking: "Im Anfang war die Tat!" (In the Beginning was the Deed!) (Goethe 1898, 50). This translation aimed at expressing the dynamic power of the Logos that everything "works and creates". Contrary to this, Faust's sentence has become a presupposition of contemporary thought according to which there is no meaning beyond human production, and thus, no meaning that is not purely contingent. The human world is certainly a meaningful universe, but its origin and foundation, whether we talk about religious narratives, value systems, social configurations, scientific theories or even human features and dispositions, is to be found neither in the "order of things", nor in human nature or divine revelation, but in a sort of self-constitutive activity by means of which human beings construct themselves and their worlds.

This fundamental insight of socio-constructionist theories in contemporary social sciences and humanities seems to pose a challenge to Christian anthropology. For being created in the image and likeness of God implies that human life receives its meaning, shape and orientation from a source other than mere human activity and creativity. This means that there is a fundamental order of meaning that, even if it can never be fully expressed by means of human concepts and language, is communicated to human beings as a way of grounding of our humanity. The Logos, then, cannot be merely a human production, as socio-constructionism claims. It has to be, on the contrary, that which, as a source of transcendent divine meaning, makes possible every human creation.

Can this transcendent shaping power of the Logos be made understandable in the contemporary intellectual scenery, so deeply determined by socio-constructionist insights? I want to argue that the idea of social construction offers a relevant place for the dialogue between Christian 
thought and contemporary social sciences. This dialogue can help both to understand better the historical character of human beings and to limit and redirect the radical insight of socio-constructionism, in a way that avoids the insurmountable problems to which it seems to lead. I will suggest that the socio-constructionist account of the origin of meaning not only leads to serious inconsistencies, but that it presupposes a pre-existing order of meaning in which we can discover the sign of the transcendent character of the Logos and the active presence of the Spirit, which makes possible and guides human historical and contingent participation in reality.

\section{The beginning as the invention of foundations}

The idea of social construction forms part of an attempt to overcome a previous image of knowledge, society, humanity and the world based on the assumption that there exists an independent reality that can be discovered and described objectively, from a universal point of view detached from all values, interests and interpretations, as well as a universal human nature which can ground moral principles and social configurations. This idea radicalizes what in the turn from the $19^{\text {th }}$ to the $20^{\text {th }}$ century was called "historical consciousness", to the point that the diversity and permanent transformation of worldviews, religions and cultures comes to be seen as an indication that proves that all what counts as real and natural is so only within entirely contingent forms of life and discursive schemes. Indeed, the core insight behind the claim that something is socially constructed is that that which appears as purely given, natural and inevitable "need not have existed, or need not be at all as it is [since it] is not determined by the nature of things" (Hacking 1999, 6; cf. Burr 2003, 45).

What exactly it means to be socially constructed, how the construction is carried out, which ontological status socially constructed things enjoy and what political consequences the whole constructionist discourse has are issues that differ in different socio-constructionist theories. However, the metaphor of construction always involves the idea that at the origin of what counts as real and human activity plays the primordial part. Ways of 
knowing, language, discourse and practice constitute reality rather than discover, represent or ground themselves in it. The point is not, of course, that our words, concepts and beliefs about the world (social or natural) are socially constructed, in the sense that they are inescapably historically and culturally shaped, but that since they are so, they cannot refer to any extra-cultural reality. That means that there is no way to discriminate between our beliefs and the external world to which they are supposed to correspond.

This conclusion, interestingly, represents a problematic move from epistemology to ontology, typical of socio-constructionism (cf. Smith 2010, 152). The full argument appears clearly in the following passage by Nelson Goodman, who in this regard comes very close to radical socio-constructionism:

Frames of reference [...] seem to belong less to what is described than to a system of description [...] If I ask about the world, you can offer to tell me how it is under one or more frames of reference; but if I insist that you tell me how it is apart from all frames, what can you say? We are confined to ways of describing whatever is described. Our universe, so to speak, consists of these ways rather than of a world. $(1978,3)$

There is no direct access to the world. All we can say and experience is mediated through our conceptual systems and ways of seeing, which are culturally and historically determined. But, - and here is where the move becomes problematic- from this extensively held position, the conclusion is drawn that our concepts and beliefs do not refer to any extra conceptual reality, because they themselves constitute reality. This step resembles George Berkeley’s master argument for idealism (cf. [1710] 1982, §22, 23; Hacking 1999, 24). What would be the world independently of our ways of knowing and our forms of life? This is, literally, unthinkable. Because every time we conceive of an aspect of reality we conceptualize it, and this implies the use of certain concepts, a particular language and frame of reference. Then a reality independent of our conceptualizations is well beyond our reach. It does not even make sense as a regulative hypothesis. "When we strip 
off as layers of convention all differences among ways of describing it, what is left? The onion is peeled down to its empty core.” (Goodman 1978, 118)

Or to put it in another famous anti-realist argument: truth cannot be a relationship of correspondence between our descriptions and beliefs about the world and some independent facts, because there is no way to establish the facts that would make true our beliefs without "constructing" the facts using the same beliefs that we want to evaluate. We cannot stand outside our language, conceptual schemes and modes of knowing in order to corroborate the correspondence between them and an external reality. A fact -according to the very etymology of the word-is something made, a product of our interpreting and not its support. Truth has to do only with the internal coherence and practical usefulness of our theories, which are ways of structuring the world for our needs, interests and actions. (cf. Gergen 2001, 54, 72, 154; Von Glasersfeld 1984; Rorty 1989, 5ss).

In a word, contingency, as one of the main characteristics of that which is claimed to have been socially constructed, implies three interrelated ontological theses: (1) what is constructed owes its existence to a particular and transitory language, culture or conceptual scheme which, unable to correspond to the way things are, constitutes them to serve particular needs and interests; therefore, (2) what is constructed is not necessary or inevitable and lacks any immutable essence; and (3) it somehow depends on human volition and activity to construct, deconstruct and reconstruct reality.

In this regard, Stephen Turner has adequately pointed out in his study of the theories of practice that:

In postfoundationalist writings in the humanities, the diversity of human practices has become a place-holder or filler in the slot formerly occupied by the traditional 'foundationalist' notions of truth, validity and interpretive correctness. Truth, validity and correctness are held to be practice-relative rather than practice-justifying notions. Where we used to say that our practices, for example in science, were justified by the fact that they led us to truth, now we can see that truth is only that which our practices of representation enable us to construct as true. [...] If practices are diverse and therefore 'local', then truth and validity are themselves local [...] [and] 'socially constructed.’” $(1994,9)$ 
Thus, to claim that the horizons of meaning in which we dwell are social constructions means that they have no foundation deeper than or beyond human activity. As an attempt to overcome foundationalism, this should mean that they are not derived from or justified by appeal to a first basic belief or principle, self-evident for "all rational beings" or objectively given to the cognitive apparatus. On the contrary, truth, validity, correctness and all other normative criteria are not only internal to particular systems and worldviews, but they are arbitrary with respect to the world (or rather they are equally valid ways of constructing the world without reference to any non-constructed reality). Foucault, for example, following Nietzsche ([1873] 2010), has attempted to show that truth, knowledge, the epistemic subject and the like are "invented" through social practices, which means that rather than an origin in human nature or the world they have a small, low, mean and unavowable beginning in dark power relations (cf. 2002, 7).

Surely, the linear image of rationality and knowledge typical of classic foundationalism is problematic and inadequate in many respects. But this does not lead to the radical conclusions of socio-constructionists. In particular, the ontological conclusion derived from the awareness of our finitude simply does not follow. Not only does the historical character of a concept not imply that it cannot refer to anything extra-conceptual, as if language, discursive practices and forms of life were walls that separated us from the world (1.1.); but also, the step from the perspective character of every cognitive activity to the ontological conclusion of the constructed character of all reality leaves unresolved the very issues regarding the origin of meaning that it seemed to explain and cannot attain its liberating goals (1.2.).

\subsection{The priority of meaning in knowledge}

The basic principle of foundationalism, according to which a belief is justified (and thus constitutes knowledge) only if it can be inferentially based upon another justified belief, and thus up to a basic belief which should be able to demonstrate its self-evident truth, implies an indefensible view of the relationship between the knowing agent and the world. In particular, this 
view of knowledge presupposes the idea of a disengaged agent (Taylor 1993). This is an agent whose primordial way of interacting with reality is cognitive; that is, through a set of operations that allow her to elaborate a picture of the world by means of the processing of bits of information taken from the surroundings, which in turn let themselves to be grasped and processed independently of any value, interest and purpose of the agent (Taylor 1993, 320). Knowledge, for this view, could be safely grounded on the neutrality of the given and the objectivity of the process of checking and connecting beliefs, which depends on the careful exclusion of all prejudice and distortion coming from the particular historical situation of the agent, as well as from her subjective constitution. On the one hand, the beliefs coming from tradition, based on authority rather than on methodical demonstration, and on the other hand, the feelings, interests and values of the agent represent prejudices that must be expelled in order to warrant objectivity. Rationality is linked thus to a method for inspecting and warranting beliefs, and the world is reduced to a constellation of objects from which all "secondary properties" are excluded as mere projections and illusory ways of being affected by the real, intrinsic properties of the objects.

But neither would knowledge be possible independently of all situation and perspective, nor can the world be understood primarily as a collection of neutral objects. Both points have been extensively elaborated in contemporary thinking and here I can just remind the reader of some basic ideas, particularly those that seem conducive to socio-constructionist conclusions. The situated character of rationality and knowledge has been particularly explored in hermeneutics in a way that also reconstructs the idea of an objective world. Against both the Enlightenment ideal of a disengaged rationality and the positivist assumption of an absolute scientific method, authors in this school have shown that all scientific investigation and rational activity, as well as all our dealings with the world, presuppose as their condition of possibility a fore-understanding of that which is going to be studied and acted upon. The life world of meaningful experience in which the scientist moves and acts provides the framework for research. It is the "horizon of what in the given case is indubitably valid as existing [...] [and 
works] as the source of self-evidence, the source of verification." (Husserl 1970, 110, 126) This horizon of pregiven meanings is embodied in culture, tradition and forms of life. But this, far from representing a hindrance for true knowledge, makes it possible. This is so for two reasons.

Firstly, as Gadamer has shown, rationality cannot be understood as a method that requires the separation from traditional and cultural values and interpretations. On the contrary, it always needs to start and work with what is given in a tradition. All interpretation and rational activity is thus historical, insofar as it begins from something that has already been understood and is previous to all further thematization (Gadamer 1975, 268, 278; cf. Heidegger 1963, § 32). This previous element of meaning Gadamer calls prejudices. But contrary to the Enlightenment's understanding of them, prejudices are not necessarily false and distorted beliefs accepted on mere authority, which would negatively limit rational inquiry. Rather, they represent the way in which the tradition has interpreted the world, and their continuity and acceptance are not an act of blind obedience but of free rational assent (Gadamer 1975, 282). Now, prejudices can be false or true with respect to the thing that is interpreted in them (Gadamer $1975,281,270)$. For that reason, understanding is always an open activity that starts from what is given in tradition but does not stop there. The horizon of fore-understanding is continuously transformed and enlarged by means of new interpretations. Accordingly, the historical character of rationality means not only that it is always situated, but also that it is open to permanent transformation, establishing new horizons of meaning that will be the basis for future interpretations.

Secondly, the historicity of rationality, its embeddedness in tradition and culture, implies that the world for human beings cannot be understood primarily as a collection of value-free objects. The fore-understanding that constitutes the starting point and the condition of possibility of all rational activity is already a way in which the world is integrated as a meaningful whole. But this integration that takes the form of tradition is far from an arbitrary imposition of meaning on reality, as if it were an entirely passive raw material ready to be shaped by humans in all possible forms and directions. 
Here is where socio-constructionists make a problematic move from the awareness of the historicity of all understanding to the conclusion that all reality is humanly constructed. For the organization of meaning in tradition is not something like the production of a picture that could be formed independently of our relation to the world, something as a representation made by a disembodied agent who could decide at will what to believe. On the contrary, the primordial form of fore-understanding is practical. It is embedded in our "skillful coping with the world", because "at the most basic, preconceptual level, the understanding I have of the world is not simply one constructed or determined by me. It is a "coproduction» of me and the world" (Dreyfus and Taylor 2015, 93) - one that is shared by others, we should add.

Accordingly, our understanding of the world is shaped by the values, beliefs and interpretations of the culture to which we belong, as well as by our interests and the practices in which our dealings with the world are structured. In this sense, there is, for us, no knowledge of the world independently from our interpretations, interests and forms of life. But the inverse is also truth. Our practices and interpretations cannot have the form they have and constitute a way of masterful dealing with the world unless the world manifests itself in them, allowing itself to be grasped in some of its aspects and modes of being. There can be no absolute knowledge of the world, because all knowledge entails the historical fore-understanding proper of certain particularly located mode of interaction with the world, but each interpretation is not an arbitrary invention of meaning. Meaning can only be the result of a practice because the practice is a skillful way of grasping and using for certain purposes certain aspects of its objects. Thus, our language, discursive practices and cultural conceptual schemes should not be understood as barriers that block our access to the real, but as the point of interaction and contact by means of which we participate in reality. All this allows for realist criteria of knowledge and truth, which also accept historicity (Gómez 2017). Evidently, certain purposes, interests and ways of seeing may deform and misuse reality, but this can only be said because reality resists certain uses and interpretations and frustrates many of our purposes. 


\subsection{The inscrutability of the origin of meaning and the unattainable promises of anti-essentialism}

In a basic and unproblematic sense for contemporary self-understanding, all of us become humans by means of being initiated in a particular world of meanings pre-existent to each individual. We all have to learn a language, form ourselves gradually as members of a particular sociocultural milieu, and, in general, become active participants in a particular life world. This implies learning to see and evaluate situations using certain values and principles, acquiring certain beliefs which work as tacit assumptions of our thought, and developing the skills and habits for skillfully coping with our particular culturally shaped environment. Clearly, the elements that compose the life world in which we are socialized and which determine the way in which every person thinks, feels and acts, have a historical character. They are not the same in every time and place, and we ourselves contribute to the permanent transformation of the horizon of fore-understanding, to use the technical term in hermeneutics, from which we interpret the world and our place in it (cf. Habermas 1981, 202, 211). So in this sense, a socially constructed world of meanings is at the origin of our becoming who we are, and human action is at the heart of the process of transforming life worlds.

But beyond the notion of socialization, an infinite regress seems to be the fate of socio-constructionism. For no radical beginning is thinkable in its terms, since that would imply identifying something from which construction started, e.g. a first raw uninterpreted material (cf. Searle 1995, 55), or that which makes the construction possible, such as an anthropological or biological constant (cf. Berger y Luckman 1967, 49, 51), or a causal process lawfully regulated (cf. Elder-Vass 2012, 14). For this reason, socio-constructionists prefer an infinite regress of constructions rather than "search for a universal or necessary beginning [that] is best left to theology" (Goodman 1978, 7). More importantly, the socio-constructionist perspective has to understand itself as a social construction. This means that we cannot take it to refer to facts in the world, but as a way of producing those very facts. ${ }^{1}$

1 Cf. Latour $(1987,17)$, according to whom "the settlement of a controversy is the cause of Nature's representation, not its consequence”. 
But then, the fact that the facts about social construction are merely social constructions is also a social construction, and this new fact too and thus to infinity (Kukla 2000, 73).

Clearly, this presents a serious obvious problem regarding the epistemic validity of a radical socio-constructionist perspective. If it is as contingent as every other possible theory, why should we adopt this view? After all, it can only offer elements for (self-defeating) radical skepticism, but not an account of the dynamics of human historicity or a description of any "real" feature of the world (cf. Smith 2010, 136; Wolterstorff 2014, 37). Some socio-constructionists are aware of this problem and have tried to offer a response. Peter Berger and Thomas Luckmann, in their seminal, though certainly not a radical socio-constructionist book, The Construction of Social Reality, decide to leave aside this sort of issues, since "to include epistemological questions concerning the validity of sociological knowledge in the sociology of knowledge is somewhat like trying to push a bus in which one is riding." $(1967,13)$ David Boor offers what may be the only possible solution to the dilemma, which implies a drastic departure from the radical socio-constructionist assumption that knowledge is not based on how things are since it is not representational but constitutive of reality. To affirm that knowledge is socially determined, that is, that it has social causes, does not imply to affirm that it cannot be true with respect to the world (Boor 1976, 14). Differently put, the fact that all our cognitive activities are situated and carried out using the particular conceptual and linguistic equipment of a culture does not mean, as we showed in the last section, that they constitute reality or that they are not forms of contact and interaction with an independent world.

The infinite regress seems insuperable for social-constructionists without giving up some of their core radical insights. But proponents of socio-constructionist anti-foundationalism normally argue that their point has to do more with politics than with epistemology or ontology. The unmasking of something that seemed natural but now is seen as socially constructed is supposed to liberate us from its dominion and to transform the status quo, which has been created as a way to reproduce and expand 
power relations (cf. Hacking 2000, 6, 53; Gergen 2001, 27). Anti-essentialism, thus, comes as a promise of liberation.

This implies an additional premise in the socio-constructionist argument. It is not only that what is constructed is contingent insofar as it is not by nature, but there is also something wrong in all construction, something "small, low, mean and unavowable" (Foucault 2002, 7) in our beginning. It is power that produces us, exclusion, domination (cf. E.g. Butler 1995, 47; Hacking 1999, 6). Reality is not only contingent because it may have been otherwise, but it is very bad as it is. This is the real point and motivation of radical socio-constructionism, what Vivien Burr calls the "liberating promise of anti-essentialism": "If what we take ourselves and others to be are constructions and not objective descriptions, and if it is human beings who have built these constructions, then it is (at least in principle) possible to re-construct ourselves in ways that might be more facilitating for us (....) it becomes possible to think not only of individuals re-construing aspects of themselves, but of re-thinking whole social categories, such as gender, sexuality, race, disability and illness”. (Burr 1998, 13; cf. Gergen 2001, 10)

There are at least three points to note here. Firstly, this additional assumption of the dark forces behind social construction is certainly not an empirical observation. Despite the effort to reconstruct the historical processes of formation of concepts, practices, subjects and theories as if this proved the assumption, it is not something we discover when we look at history. Rather it works as a presupposition that directs the interpretation of historical events. It is a way of seeing history, which has different sources in ninetieth century thought. Clearly, there is a strong Marxist influence that generates the methodological supposition "that the most important forms of action or interaction for analytic purposes are those which take place in asymmetrical or dominated relations, that it is these forms of action or interaction that best explain the shape of any given system at any given time” (Ortner 1984, 147). The reception of Freud's work also plays an important part in the constitution of the assumption, since he "let us see the moral consciousness as historically conditioned, a product as much of time and chance as of political or aesthetic consciousness.” (Rorty 1989, 30) Equally 
so does Nietzsche, for whom the universe "is for all eternity chaos, not in the sense of a lack of necessity but of a lack of order" (2001, § 109), and "life aims at semblance, I mean error, cheating, dissembling, delusion, self-delusion", so the will to truth is "a destructive principle hostile to life" (2001, § 344).

The point is that the assumption of an unavowable beginning of what is constructed comes very close to an implicit metaphysical presupposition about the nature of reality and in particular of the historical process. As such, it is not a conclusion of an argument, but the assumed beginning of a way of thinking. It cannot be demonstrated, because it grounds and limits all that can be meaningfully said once we have accepted it (cf. Collingwood 2014). Here again, radical socio-constructionism faces a dilemma. For it is not clear how it can avoid generating an ontological commitment with a view of the historical process as essentially lead by power relations and with a notion of contingency that makes it look like a real property of the world, almost a substance endowed with causal properties, rather than with a lack of something, with the absence of foundations, or sufficient causes or determination (cf. Evers 2015, 222). But such an ontological commitment would be contradictory both with its anti-foundationalist aspirations and with its epistemological skepticism regarding the possibility of knowing how things really are. And again, if this basic assumption is only one possible interpretation of reality among many, why would we accept it? Because it is liberating?

With this we arrive to the second problematic aspect of the pretended liberating character of the socio-constructionist view. Certainly, power is commonly exercised through discourse; certain interpretations and classifications construct people in a way that keeps them dominated and alienated. Racist, ethnocentric, colonialists, chauvinistic practices have normally been accompanied by justificatory discourses and ideologies that claim to be based on a description of how people, history, culture, knowledge or religion really are. This is a fact that must be always remembered and fought against. But, in order to identify certain practices and interpretations as deforming, alienating, dominating and the like we need to use criteria that can adjudicate over different culturally determined systems 
of value and belief, in a way that does not impose on them alien principles. Obviously, if all normative criteria are merely contingent constructions in the socio-constructionist sense, that is, mean and suspicious strategies of domination, then no criticism or liberating promise is possible at all (cf. Smith 2010, 138). What dark interests does the liberating promise of anti-essentialism serve? - This is the question any sensitive, self-reflexive radical socio-constructionist should ask herself.

The presumed authoritarianism of truth, universality and fixed essences cannot be overcome by unmasking the constructed character of all truth, universality and essence. On the contrary, "all that is left in this approach for the making of moral commitments are personal preference, arbitrary choice and power to enforce and impose." (Smith 2010, 141) Precisely, the critical power of truth requires not only the awareness of the fallibility of human ways of knowing, theories and discourses, and thus it is compatible with pluralism, but also the moral commitment not to decide matters based on personal preferences, arbitrary choices and power impositions. It is in the search for what is beyond these that real and liberating criticism can be performed.

Finally, the liberating promise faces an additional paradox. It has to do with the possibilities, presuppositions and limits of the enormous task of re-constructing oneself and the aspects of reality that were unmasked as social-constructions. This is certainly a capital task in all authentically human life. As existentialist authors pointed out, this lies at the heart of human responsibility, as well as of political and ethical life. But, how is the self-reconstructive job to be carried out by an entirely constructed subject by means of entirely constructed values, criteria, drives and inventions in a way that does not reproduce the very dark beginnings from which she wants to liberate herself? As in the case of the possibility of criticism, the possibility of a real liberating self-transformation requires the discovery of a different source of the self and reality that escapes construction and may well ground it.

The discussion so far suggests that the metaphor of social construction leaves unresolved problems and conduces to multiple aporias, when it is 
offered as an account of the origin and foundation of meaning. Something beyond construction is required for it to work. In order to track this sign of transcendence, we turn now to explore that which constitutes the very process of construction: the deed.

\section{The deed}

There is no consensus about how the process of social construction is carried out or what it is that constructs reality. The preferred candidates are culture, language, discourse and knowledge. We cannot explore them all here (cf. Elder-Vass, 2012), but it is important to note they have in common that all are considered as forms of practice. The concept of practice, which since the last decades of the twentieth century has become the cornerstone of social theories, is also multifaceted and polysemous. We can however identify some important features of this concept for our discussion: a practice is a habitualized pattern of actions, whose performative character has the causal power of shaping reality, the self and the social world in a way that situates contingency in the void left by essences, truth and permanent foundations after the collapse of foundationalism.

Accordingly, practices are not mere sequences of action (e.g. instinctive or automatic), but rather constitute patterns of purposive, understandable behavior. In this sense, practices require the habitualization of certain actions and something like their codification. If this is so, how can practices be the core of the social construction of universes of meaning? Rather, they presuppose the meaningful order of the social world to which they belong, and which they contribute to reproduce and transform. This circularity of meaning, the fact that practices are already significant within a certain horizon of fore-understanding (whose construction they are supposed to explain), corresponds to the infinite regress in the beginning of constructions that we mentioned earlier. Berger and Luckmann's influential theory of the construction of reality offers an interesting example of this circularity.

Certainly, the "reality" whose origin in social construction they are trying to show is not the whole of reality, but the "sense of reality", that is, the 
"quality appertaining to phenomena that we recognize as being independent of our own volition" (Berger and Luckmann 1967, 1), such as institutions, values and symbolic systems. Their theory, thus, is compatible with realist social science insofar as they differentiate the social from the natural world and accept there are certain anthropological and biological dispositions that are not constructed but make construction possible (world-openness, instinct under determination, plasticity, the need to externalization, sociability, linguistic capability, etc). But, their realist assumptions tend to be absorbed by the rest of the theory insofar as what counts as real cannot be determined independently of the forms of knowledge proper of a social group, which, in turn constitute the very sense of reality of the objects known.

The circularity of meaning in Berger and Luckmann's account of practice occurs in the following form. They offer a narrative of the origin of the social world, according to which, social reality is constructed in a process that goes from externalization to objectivation to internalization. Externalization is a sort of anthropological need to act in the external world, which has as its basis the original biological plasticity of human behavior. Contrary to what happens with other animals, the human relationship with the environment is open; this means that human action is not fixed by instinctual patterns but can acquire multiple forms and directions. This is so because the human organism is "very imperfectly structured by his own biological constitution", and thus "man constructs his own nature, or more simply, [...] man produces himself” (Berger and Luckmann 1967, 47, 49). But this self-production is always a social enterprise. Human beings must finish their ontogenetical development after they are born, in relationship to their specific social environment, which provides the stability to human conduct that it lacks due to is primordial plasticity (Berger and Luckmann 1967, 51).

So, the point is that externalization cannot be at the beginning of the process of the construction of social reality because it needs the social order to work. On the one hand, the "Social order is not part of the «nature of things», and it cannot be derived from the «laws of nature». Social order exists only as a product of human activity." (Berger and Luckmann 1967, 52) And on the other, human activity needs the social order to "specialize 
and direct his drives" (Berger and Luckmann 1967, 52). It is true that the authors insist that the relationship between human beings and society is dialectical insofar as each is a product of the other, and thus, again, no radical beginning of society in a non-social state of humanity is thinkable. But, simultaneously, the theory wants to explain how it is that social reality is a product of human action. The point is not only how reality is reproduced, but how it is produced, that is, how it is that human beings create their own nature and their world.

The key concept here is habitualization. This is the tendency towards repetition and the instauration of routine patterns proper of human action, by means of which “choices are narrowed" (Berger and Luckmann 1967, 53) and the direction and specialization of activity is attained. The social order emerges as a result of the institutionalization of habitualized actions, that is, of the typification of actions by types of actors, through the reciprocal assignation of motives. Since these typifications are available to anyone in the group, they serve to control and direct human conduct generating a way to predict each other's actions. When they have to be transmitted to the new generations, institutions become crystallized as if they had a reality of their own that "confronts the individual as an external and coercive fact." (Berger and Luckmann 1967, 58) This is the moment of objectivation, which is followed by the consequent reabsorption of the world that has been thus constructed by each individual, which is called internalization. Only at this point language enters into the picture, as well as the symbolic universes of myth, knowledge systems and moral values, which appear as legitimation instances that must explain and justify the created order to the new generations. Symbolic universes provide a unified narrative of the meaning of institutionalized actions, which gradually constitutes the pre-theoretical knowledge of the social world that all share and take for granted, and which regulates behavior. This common horizon of meaning not only provides the necessary orientation for survival and social life integrating individual into a shared frame, but also gives coherence and plausibility to the totality of the social order, as wells as to each individual life (Berger and Luckmann 1967, 84-94). 
The problem is that this theory has not been able to show that the origin of this common horizon of meaning that confers coherence and sense to collective and personal life is a product of externationalization. Rather, it has revealed that significant human action cannot be conceived without presupposing a horizon of meaning into which it is integrated. For the actions that are to be typified are already the significant actions of previously socialized actors. Interestingly, Berger and Luckmann recognize this before describing institutionalization:

We are thus for the moment excluding the cases of Adam and Eve, or of two "feral" children meeting in a clearing of a primeval jungle. But we are assuming that the two individuals arrive at their meeting place from social worlds that have been historically produced in segregation from each other, and that the interaction therefore takes place in a situation that has not been institutionally defined for either of the participants. (Berger and Luckmann 1967, 56)

What is then the point of the theory? Clearly, the origin of the social order has not been explained as emerging from human action. All that has been described is how a new social order can emerge from the interaction of actors belonging to previous universes of meaning. Maybe this is all that social construction means: the transformation and reconfiguration of social reality starting from both biological and anthropological constants, as well as from pre-given universes of meaning. But the pre-eminence of meaning over human action reveals something about both the nature of action and the foundational character of meaning: its transcendence, which is just what the religious awareness discovers. The common reference in indigenous cultures to myth as the Word of origin, as well as the Biblical account of creation through Logos, points in this direction. Human primordial world-openness and plasticity not only generate biological needs, but are also signs of transcendence. A fundamental order of meaning has to be received, discovered and followed for human action to become significant in the relevant way that allows it to participate in the social construction of reality (cf. Pannenberg 1985, 513, 321, 395, 513). 


\section{Historical contingency and the action of the Spirit}

How does this the transcendence of meaning relate to historicity? The contingent character of our belief systems, modes of being human and forms of life, we have seen, cannot be reduced to arbitrariness, self-reference and dark beginnings. However, as socio-constructionists claim, they are neither inevitable, nor necessary, and they are open to permanent transformation and re-construction. This openness, nonetheless, is not self-sustaining. It always presupposes an order of meaning that directs the process, as well as and order of being in relation to which the process can be carried out. Historicity is this open-ended process of reconstruction guided by meaning in which human beings take part. How can we understand this process? To finish I would like to offer some suggestions, which need further elaboration, aimed at reinterpreting the most significant socio-constructionist insights from a theistic perspective.

To be guided by meaning should not be understood in a deterministic sense, as if history were programed to follow certain pre-established path. On the contrary, the plasticity of human behavior, due to its biological underdetermination, requires that humans construct the meaning of their environment and their lives taking resources from both natural (genetic) and cultural sources of "information" (Hefner 1993, 146). I agree with Philip Hefner's claim that "myth and ritual are the chief carriers of the information that motivates and interprets the behaviour beyond the biogenetic" (Hefner 1993, 149). As foundational orders of meaning, as we have seen, they cannot be reduced to some pre-significant type of action or practice. This irreducibility gives the perspective of the believer hermeneutical priority: in myth and ritual the divine manifests itself to human beings. They provide the orientations and models for human life, which however are historical. This means that instead of simply disclosing what human beings are once and for all, they open a direction for human becoming. In religious narratives and practices an invitation is issued and a task is set for humans to realize and become what they are called to be. For this reason, human becoming is always a participative and co-creative responsibility and task. 
As Wolfhart Pannenberg has shown, this is a central aspect in the Christian understanding of human beings as historical creatures. Contrary to the Greek identification of the truly real with eternal, immutable essences, the belief in the New Creation, and particularly the notion of the "second man" (Cor. 15: 47), implies a radical new understanding of the human person, not as confined to a fixed nature, but as a project oriented towards the eschatological future in which we will reach the plenitude of our being (Pannenberg 1985, 496-502). Human historicity thus implies that human existence is decided in and through the events of a concrete history, rather than by an essential nature. But this openness requires, as the condition for the very historical production of human identity, the awareness of a totality of meaning that provides unity to each subject and to the very process of history (Pannenberg 1985, 514).

Like for socio-constructionist, narratives provide this totality of meaning. But while for them the narrative constitution of human reality is the clearest sign of its lack of foundations, from a Theistic perspective it is an indication of the historical action of the Spirit in human life. Let us examine this assertion.

For socio-constructionist the power that practices have to "produce reality" (even though it is differently interpreted in each theory) refers to their capacity to structure experience, identity, subjectivity and the body through historically contingent concepts and categories. Thus, the productive character of practices, their creative power, consists in a sort of imposition of structure and arbitrary characteristics into a reality that lacks any inner nature and lets itself be shaped at will by human actions and interpretations. Burr summarizes this view when she affirms that language "provides us with a system of categories for dividing up our experience and giving it meaning, so that our very selves become the products of language. Language produces and constructs our experience of each other and ourselves" $(2003,62)$.

In a more radical sense, this means -as Michel Foucault puts it- that the very objects of discourse are not simply there ready to be grasped, used and conceptualized, but emerge from the complex net of relationships that make it possible to speak of and deal with them $(1972,46)$. So there is no 
need for raw material that supports construction. In his words: "We sought the unity of discourse in the objects themselves [...] in what is given to the speaking subjects; and in the end, we are sent back to a setting-up of relations that characterizes discursive practice itself; and what we discover is neither a configuration, nor a form, but a group of rules that are immanent in a practice, and define it in its specificity”. $(1972,46)^{2}$

But this displaces the question to: what kind of reality do our reality-constructing discursive practices have? And where do they derive their reality from? Radical socio-constructionism not only denies all real alterity, all otherness in reality (which is an irony for theories that want to defend and exalt multiplicity, difference and marginality), putting human action at the center of reality (which is paradoxical for philosophies that aim at overcoming the primacy of modern conceptions of the subject, its autonomy and foundational character); but it also postulates as real something that cannot ontologically ground itself. If language is an ever changing closed system not connected with the world, neither can power relations produce it, nor can it constitute domination strategies or have any causal power whatsoever to affect reality. For the existence of a world with its own mode of being is a condition for any causal power or productivity of language and discourse, a world that includes us as well as our language, our knowledge and our forms of life. We are part of and participants in reality, and thus even our ways of interpreting and transforming it count as the way things really are (cf. Elder Vass 2012, 247; Evers 2015).

It is no doubt paradoxical to claim that our discourses totally construct their objects assuming, simultaneously, that we can study discursive orders, that is, that we can analyze the way in which certain objects have emerged

2 Interestingly, Foucault explains that referents are not completely lost for him. He recognizes that a "history of the referent is no doubt possible; and I have no wish at the outset to exclude any effort to uncover and free these 'prediscursive' experiences from the tyranny of the text. But what we are concerned with here is not to neutralize discourse, to make it the sign of something else [...] but to make it emerge in its own complexity." $(1972,47)$ This approach, as a methodological principle that abstracts discourse from its wider entanglements in reality, has certainly opened a fruitful and insightful path for contemporary thought. But a methodological strategy does not justify the jump unto ontological conclusions. 
as objects of discourse. Are the studied discursive orders also constructed by the new meta-discourse that attempts to study them? -Here again an infinite regress and the issue of the epistemological validity of radical socio-constructionist theories loom. Discursive processes of social construction must themselves be as independently real as anything can be, if they, one the one hand, have the causal power they are claimed to have to shape reality, and on the other, if they can be studied.

The irreducible alterity of reality, which both resists certain interpretations and includes our multiple life forms and dynamic interactions with the environment, complements the transcendence of meaning we discovered before. Human practices cannot be completely self-generative and self-sustaining, but presuppose an order of meaning and an order of being that precede and ground our dynamics of interpretative and reconstructive participation in reality. Moreover, it is the alterity of reality that keeps linguistic reference open, since reality cannot be fully and wholly grasped in concepts. The permanent transformation of our worldviews, theories and cultural configurations is just a manifestation of the permanent dynamic character of our relation to the world. Thus, the contingency of human historicity should not be interpreted as a sentence to perpetual intellectual homelessness, due to the impermanence and arbitrariness of every belief system and universe of meaning. On the contrary, it may be seen as the expression of the relational character of reality of which we form part.

Moreover, the historical production of worldviews and modes of being human, which is narrative based, can only work by means of anticipations of meaning. This is, by integrating all particularities in bigger pictures from which they receive their significance. The basic interpretations of the world and ourselves that this pictures offer always have a mythical character, in that they provide an order of meaning that is assumed and cannot be grounded or reduced to anything else. Even a picture of reality as mere flux and contingency is a picture in this sense, but it has the insuperable disadvantage of assigning to human practice what it cannot do on its own: to ground reality.

On the contrary, the totality of meaning that theistic narratives and practices offer makes it possible to participate in the construction of reality 
as co-creators (Hefner 1993). This is so because they imply both discovering "the presence of the true and definitive amid the processes of history that always break off uncompleted" (Pannenberg 1985, 519), and the task to achieve the unity of history acting in it with an orientation towards the salvific future. Thus,

If the human race is to be a formative process leading to a fulfilled humanity, it can be such only under the guidance of divine providence.

This guidance need not, of course, be understood as a determination of events prior to the actual course of history [...] Rather, an understanding of God as the goal of history and [...] and understanding of God's aims in dealing with humankind can inspire their anticipation of the final form of human identity and thus the orientational framework in which they decide on the goals of their own action. (Pannenberg 1985, 515)

The contingency of human historicity, the fact that human beings need to participate in their own self-constitution and that our constructions are always transient and changeable, can be interpreted as the open space for God's action in the human world. Because "God strives for and reaches his ends not apart from human beings but with the cooperation of his creatures and through the conflicts between human purposes and interests." (Pannenberg 1985, 515) In this connection, a theistic reinterpretation of social construction can be developed, which both avoids the aporias of its radical forms and enriches the Christian understanding of human beings as historical creatures, this is, as created co-creators guided by transcendent meaning.

\section{References}

Berger, Peter and Thomas Luckmann.1967. The Social Construction of Reality. A Treatise in the Sociology of Knowledge. New York: Anchor books.

Berkeley, George. [1710] 1982. A Treatise Concerning the Principles of Human Knowledge. Indianapolis: Hackett.

Bloor, David.1976. Knowledge and Social Imagery. London: Routledge and Kegan Paul. 
Boghossian, Paul. 2006. Fear of Knowledge. Against Relativism and Constructivism. Oxford: Clarendond Press.

Butler, Judith. 1995. “Contingent foundations”, in Feminist Contentions, edited by S. Benhabib, J. Butler, D. Cornell and N. Fraser, 35-57. New York: Routledge.

Burr, Vivien. 1998. “Overview: Realism, Relativism, Social Constructionism and Discourse”. In Social Constructionism, Discourse and Realism, edited by Ian Parker, 13-25. London: Sage.

Burr, Vivien. 2003. Social Constructionism. Second edition. London: Routledge.

Collingwood, R.G. 2014. An Essay on Metaphysics. Oxford: Clarendon Press.

Dreyfus, Hubert and Charles Taylor. 2015. Retrieving realism. Cambridge Ma: Harvard University Press.

Elder-Vass, Dave. 2012. The Reality of Social Construction. Cambridge: Cambridge University Press.

Evers, Dirk. 2015. “Contingent reality as participation”. Philosophy, Theology and the Sciences 2 (2): 216-242.

Foucault, Michael. 1972. The Archaeology of Knowledge. Trans. A.M. Sheridan Smith. New York: Pantheon books.

Foucault, Michael. 2002. “Truth and the Juridical Forms”. In Power: Essential Works of Foucault 1954-1984, Edited by James D. Faubion, 1-89. London: Penguin books. Gadamer, Hans-Georg. 1975. Truth and Method. London: Continuum.

Gergen, Kenneth. 2001. Social Construction in Context. London: Sage.

Goethe Johann Wolfgang. 1898. Faust. A tragedy, trans. Bayard Taylor. Boston and New York: Houghton Mifflin.

Gómez, Carlos Miguel. 2017. “Historicidad, realismo y verdad”. Principia, An International Journal of Epistemology, 21 (1): 77-89.

Goodman, Nelson. 1978. Ways of Worldmaking. Indianapolis: Hackett.

Habermas, Jürgen. 1981. Theorie des kommunikativen Handelns. Band 2: Zur kritik der funktionalistischen Vernunft. Frankfurt: Suhrkamp.

Hacking, Ian. 2000. The Social Construction of What? Cambridge MA \& London: Harvard University Press.

Hefner, Philip. 1993. The Human Factor. Evolution, Culture and Religion. Minneapolis: Fortress.

Heidegger, Martin. 1963. Sein und Zeit. Tübingen: Max Niemeyer.

Husserl, Edmund. 1970. The Crisis of European Sciences and Transcendental Phenomenology. Evanston: Northwestern University Press.

Kukla, Andre. 2000. Social Constructivism and the Philosophy of Science. London \& New York: Routledge.

Latour, Bruno (1987). Science in Action. Milton Keynes: Open University Press. 
Nietzsche, Friedrich. [1873] 2010. “On Truth and Lie in a Nonmoral Sense”, in On Truth and Untruth, edited by Taylor Carman, 15-49. New York: Harperperennial. Nietzsche, Friedrich. 2001. The Gay Science. Cambridge: Cambrige University press. Ortner, Sherry. 1984. “Theory in Anthropology since the Sixties”. Comparative Studies in Society and History 26 (1): 126-166.

Pannenberg, Wolfhart. 1985. Anthropology in Theological Perspective. Edinburg: T\&T Clark.

Rorty, Richard. 1989. Contingency, Irony, and Solidarity. New York: Cambridge University Press.

Smith, Christian. 2010. What is a Person? Rethinking Humanity, Social Life, and the Moral Good from the Person Up. Chicago and London: University of Chicago Press. Taylor, Charles. 1993. "Engaged agency and background in Heidegger”. In The Cambridge Companion to Heidegger, edited by Charles Guignon, 317-336. Cambridge University Press.

Turner, Stephen. 1994. The Social Theory of Practices. Tradition, Tacit Knowledge and Presuppositions. Cambridge: Polity.

Von Glasersfeld, Ernst. 1984. “An Introduction to Radical Constructivism”, in The Invented Reality, edited by Paul Watzlawick. New York: Norton.

Wolterstorff, Nicholas. 2014. “The World Ready-made”. In Practices of Belief, 12-40. Cambridge University Press. 